Cite this: Phys. Chem. Chem. Phys., 2012, 14, 2483-2493

\title{
Hydration and interactions in protein solutions containing concentrated electrolytes studied by small-angle scattering
}

\author{
Fajun Zhang, ${ }^{* a}$ Felix Roosen-Runge, ${ }^{a}$ Maximilian W. A. Skoda, ${ }^{b}$ \\ Robert M. J. Jacobs, ${ }^{c}$ Marcell Wolf, ${ }^{a}$ Philip Callow, ${ }^{d}$ Henrich Frielinghaus, ${ }^{e}$ \\ Vitaliy Pipich, ${ }^{e}$ Sylvain Prévost ${ }^{f}$ and Frank Schreiber ${ }^{a}$ \\ Received 3rd November 2011, Accepted 13th December 2011 \\ DOI: $10.1039 / \mathrm{c} 2 \mathrm{cp} 23460 \mathrm{~b}$
}

During protein crystallization and purification, proteins are commonly found in concentrated salt solutions. The exact interplay of the hydration shell, the salt ions, and protein-protein interactions under these conditions is far from being understood on a fundamental level, despite the obvious practical relevance. We have studied a model globular protein (bovine serum albumin, BSA) in concentrated salt solutions by small-angle neutron scattering (SANS). The data are also compared to previous studies using SAXS. The SANS results for dilute protein solutions give an averaged volume of BSA of $91700 \AA^{3}$, which is about $37 \%$ smaller than that determined by SAXS.

The difference in volume corresponds to the contribution of a hydration shell with a hydration level of $0.30 \mathrm{~g} \mathrm{~g}^{-1}$ protein. The forward intensity $I(0)$ determined from Guinier analysis is used to determine the second virial coefficient, $A_{2}$, which describes the overall protein interactions in solution. It is found that $A_{2}$ follows the reverse order of the Hofmeister series, i.e.

$\left(\mathrm{NH}_{4}\right)_{2} \mathrm{SO}_{4}<\mathrm{Na}_{2} \mathrm{SO}_{4}<\mathrm{NaOAc}<\mathrm{NaCl}<\mathrm{NaNO}_{3}<\mathrm{NaSCN}$. The dimensionless second virial coefficient $B_{2}$, corrected for the particle volume and molecular weight, has been calculated using different approaches, and shows that $B_{2}$ with corrections for hydration and the non-spherical shape of the protein describes the interactions better than those determined from the bare protein. SANS data are further analyzed in the full $q$-range using liquid theoretical approaches, which gives results consistent with the $A_{2}$ analysis and the experimental structure factor.

\section{Introduction}

Protein interactions and phase behavior in solutions containing concentrated electrolytes are crucial for understanding the mechanism of protein crystallization or the specificity. ${ }^{1-6}$ For example, salt induced precipitation has been extensively used as an initial step for protein purification. ${ }^{2,7-9}$ However, protein solubility is not well understood on a molecular level, and selecting the optimum conditions to precipitate a target protein is difficult because the solubility is governed by many factors including $\mathrm{pH}$, surface hydrophobicity, surface charge distribution, salt type and concentration. Proteins are commonly found in

\footnotetext{
${ }^{a}$ Institut für Angewandte Physik, Eberhard Karls Universität Tübingen, Auf der Morgenstelle 10, D-72076 Tübingen, Germany. E-mail: Fajun.zhang@uni-tuebingen.de

${ }^{b}$ STFC ISIS, Rutherford Appleton Laboratory, Chilton, Didcot, OX11 $0 O X, U K$

${ }^{c}$ Department of Chemistry, Chemistry Research Laboratory, University of Oxford, Mansfield Road, OX1 3TA, UK

${ }^{d}$ Institut Laue Langevin, BP 156-X, F-38042, Grenoble, France

${ }^{e}$ Forschungszentrum Jülich GmbH, Jülich Centre for Neutron Science at FRM II, Lichtenbergstrasse 1, 85747 Garching, Germany

${ }^{f}$ Helmholtz Center Berlin, Hahn-Meitner-Platz 1, D-14109 Berlin, Germany
}

concentrated salt solutions during protein crystallization which is essential for the most efficient way of determining the protein structure, namely X-ray crystallography. ${ }^{4}$ The optimization of conditions for preparation of protein single crystals is still largely a trial and error process. Theories that can reliably predict protein solubility and crystallization conditions in a complex solution are currently not available, but understanding the factors that affect the protein interactions as well as the phase behavior of protein solution is the only way towards developing a theoretical framework that can be used to optimize or predict the desired conditions.

Small angle X-ray and neutron scattering (SAXS and SANS) as low resolution diffraction methods have been widely used for structural determination as well as understanding protein interactions in solutions. ${ }^{10-18}$ Using SANS combined with SAXS, Sinibaldi et al. studied the solvation properties of BSA and lysozyme in urea solution and water/glycerol mixtures, respectively. ${ }^{19,20}$ SANS and SAXS provide complementary information due to the different responses to the hydration shell surrounding proteins. The interpretation of SANS data requires knowledge of the hydration level and the $\mathrm{H}-\mathrm{D}$ exchange ratio of proteins. Zaccai and Jacrot discussed the 
volume determined by SANS measurement from the forward intensity, $I(0) .{ }^{21}$ They pointed out that the volume term derived from $I(0)$ includes not only the "dry" volume of the protein, but also the volume change of the water molecules from the bulk to the hydrated state. This perturbation mainly depends on the density of the hydrated water compared to bulk water. Svergun et al. studied the density of hydration shell using SAXS and SANS. ${ }^{16}$ They found that the density of the hydration shell is about $10 \%$ higher than that of bulk water. This result was supported by molecular dynamics simulations. ${ }^{22}$ Given the negative contrast of the high density hydration shell for SANS measurements in both $\mathrm{H}_{2} \mathrm{O}$ and $\mathrm{D}_{2} \mathrm{O}$, this will give a reduced size of the target protein. Indeed, the radius of gyration $\left(R_{\mathrm{g}}\right)$ determined by SAXS was found to be larger than that calculated from the atomic structure, while $R_{\mathrm{g}}$ values determined by SANS in $\mathrm{H}_{2} \mathrm{O}$ and $\mathrm{D}_{2} \mathrm{O}$ are similar to and slightly smaller compared to the calculated value. From these results, it seems that SANS is not sensitive to the hydration shell. Perkins discussed the effect of hydration shell in both SAXS and SANS measurements: $:^{13}$ For SAXS, the electron density difference between the hydrated water $\left(0.408 \mathrm{e} \AA^{-3}\right)$ and bulk water $\left(0.334 \mathrm{e}^{-3}\right)$ is similar to that of proteins $\left(0.425 \mathrm{e}^{-3}\right)$, and it therefore measures the hydrated protein molecules as a complete object. For SANS, proteins in $\mathrm{H}_{2} \mathrm{O}$ have a SLD of $0.19 \times 10^{-6} \AA^{-2},+134 \%$ compared to $\mathrm{H}_{2} \mathrm{O}\left(-0.562 \times 10^{-6} \AA^{-2}\right)$, while the hydration shell $\left(-0.69 \times 10^{-6} \AA^{-2}\right)$ has a contrast of about $-23 \%$, which is similar to the $31 \%$ variation in SLD within the common 20 amino acids with proteins, the hydration shell is therefore not detectable in a SANS experiment with $\mathrm{H}_{2} \mathrm{O}$ buffer. Proteins in $\mathrm{D}_{2} \mathrm{O}$ have a SLD of $3.2 \times 10^{-6} \AA^{-2},-50 \%$ compared to $\mathrm{D}_{2} \mathrm{O}$ $\left(6.35 \times 10^{-6} \AA^{-2}\right)$. The hydration shell (SLD of $7.82 \times 10^{-6} \AA^{-2}$ ) has a contrast of about $+22 \%$. The contribution from the hydration shell is still weak, but may not be negligible. As shown by Svergun et al. ${ }^{16} R_{\mathrm{g}}$ values determined by SANS in $\mathrm{D}_{2} \mathrm{O}$ are slightly smaller than the calculated value (within systematic error bar). It was concluded that to a good approximation, the hydration shell is not detectable by SANS in either $\mathrm{H}_{2} \mathrm{O}$ or $\mathrm{D}_{2} \mathrm{O}^{13}$ These studies indicate that there is a discrepancy between the theoretical considerations and SANS experiments and more detailed experimental studies are required to clarify this issue; and the comparison between SAXS and SANS is necessary for a comprehensive picture of the hydration shell surrounding proteins.

It has long been known that the solubility of proteins in solution depends not only on the salt concentration, but also on the type of the salt. This important phenomenological concept is known as "Hofmeister effect". ${ }^{23}$ The classification of ions was initially performed on their ability to precipitate a protein, and could be extended to many other systems. ${ }^{8}$ The order is related to many key parameters, in particular the propensity of ions to affect water structure. ${ }^{8}$ It has been shown that anions have a stronger effect. However, the combination of cation and anion in a salt does not result in a trivial sum of ion effects. A representative Hofmeister anion series can be given as follows:

$$
\begin{gathered}
\text { Citrate }^{3-}>\mathrm{SO}_{4}{ }^{2-}>\mathrm{PO}_{4} \mathrm{H}^{2-}>\mathrm{F}^{-}>\mathrm{CH}_{3} \mathrm{COO}^{-}>\mathrm{Cl}^{-}> \\
\mathrm{Br}^{-}>\mathrm{I}^{-}>\mathrm{NO}_{3}{ }^{-}>\mathrm{ClO}_{4}^{-}>\mathrm{SCN}^{-}
\end{gathered}
$$

Ions on the left hand side of the series will precipitate ("salt out") solutes, whereas ions on the right will dissolve or denature ("salt in") solutes. Hofmeister effects have been explained in terms of structure-making ("kosmotrope") and structurebreaking ("chaotrope") abilities of these ions with water. ${ }^{7,9}$ Kosmotropes interact with water strongly and water molecules surrounding the salt ions are more structured relative to bulk water. Chaotropes break up the structure of the surrounding water molecules because of the large size of the ion and its weak interaction with water. For example, the specific ion effects on protein solubility were described in terms of the ability of ions to "salt in" the polar peptide group and "salt out" the nonpolar side chains. ${ }^{24}$ Hofmeister effects on the solubility of proteins have also been related to the protein-water interfacial tension. ${ }^{25}$ Although the molecular basis of Hofmeister effects, i.e. the specific ion effects, is not yet fully understood, significant progress has been made by inclusion of dispersion forces and hydration. Simplified models of electrolytes with proper inclusion of dispersion forces can capture the essentials of Hofmeister effects qualitatively. ${ }^{26-28}$

Serum albumin is the most abundant protein in mammalian blood with a concentration around $30 \mathrm{~g} \mathrm{~L}^{-1}$. Bovine and human serum albumin (BSA and HSA) as model globular proteins have been involved in many studies due to their applications as a carrier protein and as a stabilizing agent in enzymatic reactions. BSA in solution has been studied by SAXS and SANS with various protein concentration, ionic strength, and $\mathrm{pH}^{29-33} \mathrm{BSA}$ is a good model for protein interactions in concentrated salt solutions because of its stability in a wide salt concentration range. In this context, we have studied the protein-protein interactions in aqueous solution using SAXS as a function of protein and ionic strength. ${ }^{34-37}$ The protein-protein interactions strongly depend on the nature of the added salts. When a trivalent salt was added into protein solution, a novel phase behavior, named "reentrant condensation", was observed recently in our laboratory. ${ }^{37-39}$

In this paper, we present a systematic study of protein (BSA) in concentrated salt solutions with different types of salt by using SANS, which provides high contrast and no radiation damage. By comparison with our previous SAXS study ${ }^{36}$ the contribution from the hydration shell will be specifically addressed. By using several typical salting-in and salting-out anions selected from the Hofmeister series, we address the following questions: first, how sensitive is SANS in this case to the hydration shell? By calculating the protein volume and comparing with that determined from SAXS and protein crystallography, we determine the contribution of the hydration shell. Second, how to determine the interactions in such concentrated salt solutions? The second virial coefficient is evaluated and discussed along the predictions for the Hofmeister series. Furthermore, modeling based on liquid state theory will be used to address these questions.

\section{Experimental section}

\subsection{Materials}

Bovine serum albumin (BSA) (99\% purity) was purchased from Sigma-Aldrich. It is a lyophilized powder with a molar molecular weight of $\sim 66 \mathrm{kDa}$ and was used as received. The following salts 
were used as received: sodium acetate $(\mathrm{NaOAc}), \mathrm{NaNO}_{3}$ (Sigma-Aldrich), $\mathrm{Na}_{2} \mathrm{SO}_{4}, \mathrm{NaCl},\left(\mathrm{NH}_{4}\right)_{2} \mathrm{SO}_{4}$ (Merck), $\mathrm{NaSCN}$ (Alfa Aesar). BSA solutions were prepared by diluting a stock solution of $180 \pm 1 \mathrm{mg} \mathrm{mL}^{-1}$ determined by UV absorption at $280 \mathrm{~nm}$ with an extinction coefficient of $39020 \mathrm{M}^{-1} \mathrm{~cm}^{-1}$, or $0.5912 /\left(\mathrm{mg} \mathrm{mL}^{-1}\right) \mathrm{cm}^{-1}$, calculated from the amino acid sequence. ${ }^{32}$ In order to avoid the effect of other ions, no buffer was used. The $\mathrm{pH}$ of protein solutions was $6.8 \pm 0.1$ for most salts used except $\left(\mathrm{NH}_{4}\right)_{2} \mathrm{SO}_{4}$ and $\mathrm{NaOAc}$ with $\mathrm{pH}$ values of about $6.2 \pm 0.1$ and $8.0 \pm 0.1$, respectively. All the SANS measurements were performed at $20{ }^{\circ} \mathrm{C}$ using $\mathrm{D}_{2} \mathrm{O}(99.9 \%$, Aldrich or ILL) as solvent.

Caution: It should be noted that concentrated sodium salt solutions can be radioactive after SANS measurements.

\subsection{Small-angle neutron scattering}

Small-angle neutron scattering (SANS) measurements were performed at three different stations, D22 (ILL, Grenoble, France), KWS2 (JCNS, FRM2, Munich, Germany) and V4 (Helmholtz Center, Berlin, Germany).

D22 diffractometer at the high flux reactor of the Institut Laue-Langevin (ILL) in Grenoble, France: Two configurations were used with sample-to-detector distances of $2 \mathrm{~m}$ and $8 \mathrm{~m}$ and collimation length of 2 and $8 \mathrm{~m}$, respectively, in order to cover the $q$-range from 0.007 to $0.35 \AA^{-1}$ at a wavelength $\lambda$ of $6.0 \AA$ $(\Delta \lambda / \lambda=10 \%)$. Protein solutions in $\mathrm{D}_{2} \mathrm{O}$ were filled in quartz cells with a path-length of 1 or $2 \mathrm{~mm}$. Pure $\mathrm{H}_{2} \mathrm{O}$ was used for the absolute intensity calibration. Data correction was performed using GRASP. ${ }^{40}$

SANS instrument V4 at the Helmholtz Center, Berlin, Germany: ${ }^{41}$ Three configurations were used with sampleto-detector (SD) distances of $1 \mathrm{~m}, 4 \mathrm{~m}$ and $12 \mathrm{~m}$ and collimation lengths of $8 \mathrm{~m}, 4 \mathrm{~m}$, and $12 \mathrm{~m}$, respectively, in order to cover the $q$-range from 0.005 to $0.40 \AA^{-1}$ at a wavelength of $6 \AA$ $(\Delta \lambda / \lambda=10 \%)$. The data were recorded on a $64 \times 64 \mathrm{~cm}^{2}$ twodimensional detector and radially averaged. The data reduction was performed using the software BerSANS. ${ }^{42}$ Protein solutions in $\mathrm{D}_{2} \mathrm{O}$ were filled in quartz cells with a path-length of 5 or $10 \mathrm{~mm}$. Pure $\mathrm{H}_{2} \mathrm{O}$ was used for the absolute intensity calibration.

KWS2 instrument located at the FRM2, Munich, Germany: Two configurations were used with SD distances of 2 and $8 \mathrm{~m}$ and a collimation length of $8 \mathrm{~m}$ in order to cover the $q$-range from 0.005 to $0.35 \AA^{-1}$ at a wavelength $\lambda$ of $4.5 \AA(\Delta \lambda / \lambda=20 \%)$. A two-dimensional array detector was used to detect neutrons scattered from sample solutions. Protein solutions were filled in rectangular quartz cells with path-length of 1 or $2 \mathrm{~mm}$. Plexiglas was used as secondary standard to calibrate the absolute scattering intensity. The data correction and absolute intensity calibration were obtained using the software QtiKWS. ${ }^{43}$

It is worthy to note that the absolute scale of SANS is known to be difficult to obtain with a high precision, and different set-ups and methods from different facilities might lead to slightly different absolute intensity values. ${ }^{44,45}$

\subsection{Data analysis}

SANS intensity from protein solutions can be described as:

$$
I(q)=N_{\mathrm{p}}(\Delta \rho)^{2} V_{\mathrm{P}}^{2} P(q) S(q)+\mathrm{B}
$$

where $q=4 \pi / \lambda \times \sin \theta, 2 \theta$ denotes the scattering angle, $N_{\mathrm{P}}$ is the number of protein molecules per unit volume in the solution, $V_{\mathrm{P}}$ is the volume of a single protein and $\Delta \rho=\left(\rho_{\mathrm{P}}-\rho_{\mathrm{S}}\right)$, is the difference of scattering length density between protein and solvent. $P(q)$ is the form factor of a given protein, i.e., the scattering from a single protein molecule after orientation averaging. $S(q)$ is the structure factor describing the timeaveraged interaction and distribution of proteins in solution. $B$ is the protein concentration dependent incoherent background.

Determination of the radius of gyration, $\boldsymbol{R}_{\mathrm{g}}$. In a dilute protein solution, where protein molecules are well dispersed, the interaction between them is negligible. In this case, the scattering intensity is the summation of the scattering intensities of all the proteins within the illuminated volume. At sufficiently low $q\left(q R_{\mathrm{g}}<1\right)$, the scattering intensity can be approximated by the Guinier law: ${ }^{46,47}$

$$
\ln [I(q)-B]=\ln I(0)-\frac{1}{3} R_{\mathrm{g}}^{2} q^{2}
$$

where $I(0)$ is the forward scattering at zero angle, $R_{\mathrm{g}}$ the radius of gyration. Eqn (2) provides a direct method to determine the $R_{\mathrm{g}}$. In practice, eqn (2) is valid in the range of $q R_{\mathrm{g}}$ up to $1.5 .^{14}$

Determination of the second virial coefficient, $A_{2}$. The forward intensity determined from the Guinier analysis can be used to determine $A_{2}$. Tardieu and co-workers have demonstrated that under weak interactions and low protein concentrations, the second virial coefficient can be determined from SAXS measurements. ${ }^{4-51}$ Eqn (1) can be re-written as:

$$
I(q)=c \alpha P(q) S(q)+B
$$

where $c$ is the protein concentration in unit of $\mathrm{mg} \mathrm{mL}^{-1}$, and $\alpha$ a pre-factor. The structure factor at $q=0$ is related to the osmotic pressure, $\Pi$, by:

$$
S(0)=\frac{R T}{M_{\mathrm{W}}}\left(\frac{\partial \Pi}{\partial c}\right)^{-1}
$$

where $R$ is the gas constant, and $\Pi$ can be expressed via a virial expansion:

$$
\frac{\Pi}{c R T}=\frac{1}{M_{\mathrm{W}}}+A_{2} c+A_{3} c^{2} \ldots
$$

For low protein concentration and weak interactions, the $A_{3}$ and higher order terms can be neglected, which then yields:

$$
\frac{1}{S(0)}=1+\left(2 M_{\mathrm{W}} A_{2}\right) c
$$

From eqn (3) and (6) we have

$$
\frac{1}{S(0)}=1+\left(2 M_{\mathrm{W}} A_{2}\right) c=\frac{c}{I(0)-B} \alpha P(0)
$$

Model fitting using liquid state methods. The scattering intensity, $I(q)$, for a polydisperse or a non-spherical system, is calculated based on approximation approaches. Most often used are the "decoupling approximation" and "average structure factor" approximation. ${ }^{52-55}$ Both approaches assume that the particle orientation is independent of the particle position, 
and the form factor results consistently in both approaches from the angular average of a single particle.

In the decoupling approximation, an explicit angular average for the assumed particle shape is performed and returns a scaling factor $\beta(q)$ for the structure factor. ${ }^{52-54}$ The average structure factor approximation accounts implicitly for the angular average by introducing an effective monodispersed particle. ${ }^{55}$ While this thus technically neglects polydispersity and non-sphericity, the decoupling approximation can induce more delicate errors, since it is sensitive to the actual choice of the particle shape, which is not unique if based on the experimental form factor. For the case of moderately non-spherical but monodispersed particles, such as globular proteins in solution, both assumptions were proven to give comparable results. Therefore, in this work, the scattering intensity is calculated using the average structure factor approximation. ${ }^{46,52,55,56}$

In our case, the protein molecules have an overall ellipsoidal geometry. An effective sphere radius is calculated by equating the second virial coefficient, $A_{2}$, of the ellipsoid to a sphere having the same $A_{2}$. In the latter discussion, this effective radius is called "Isihara radius", and will be used to calculate $S(q){ }^{36,37,57,58}$ BSA is negatively charged at physiological $\mathrm{pH}$. At low ionic strength $(<100 \mathrm{mM})$, the charge induced interaction can be described using a screened Coulombic potential. ${ }^{59,60}$ At moderate and high ionic strength, the surface charge of proteins is sufficiently screened. The overall interaction is rather weak, and the protein molecules interact with each other mainly through hard sphere (excluded volume effect) interactions. Detailed description can be found in our previous publications. ${ }^{36-38}$ The data analysis was carried out using macros developed by the NIST center for neutron scattering research. ${ }^{57}$

\section{Results and discussion}

\subsection{Form factor and hydration shell}

We first present the results on the shape and size of proteins in dilute solutions (below $20 \mathrm{mg} \mathrm{mL}^{-1}$ ) with an ionic strength sufficient to screen the surface charge. Since the global shape of a particle is mainly reflected in the intermediate $q$ range where the scattering intensity decays quickly as a function of $q$, a model with a simplified particle shape (sphere or ellipsoid etc.) has the advantage of using a larger $q$ range compared to the Guinier analysis. It thus provides more precise information on the size and shape of the particle. The information on the form factor is very sensitive to the fit in the $q$ range of 0.01 to $0.2 \AA^{-1}$. Data points at larger $q$ have a lower statistical certainty and are affected by the incoherent background correction, while the data points at lower $q$ are sensitive to the effects of beam stop and aggregation.

Data fitting using an ellipsoid form factor was performed on SANS data from all instruments. Fig. 1 shows the SANS data collected on V4. The SANS curves are almost identical for BSA $19.4 \mathrm{mg} \mathrm{mL}^{-1}$ with three different salts at an ionic strength of $100 \mathrm{mM}$ (Fig. 1a). The best fits using an oblate ellipsoid gives the dimension $R_{a}=12.5 \pm 0.2 \AA$ and $R_{b}=41.9 \pm 1.1 \AA$, with a constant volume fraction of $(1.1 \pm 0.1) \%, \Delta \rho=-(3.3 \pm 0.2) \times 10^{-6} \AA^{-2}$ and incoherent background $0.01 \mathrm{~cm}^{-1}$. In the literature, ${ }^{30,32}$ BSA has been

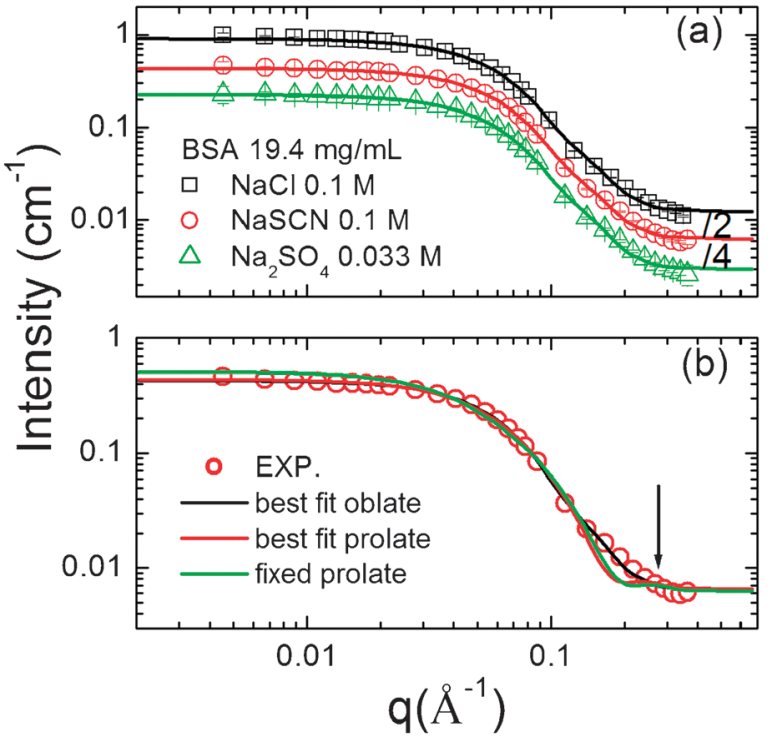

Fig. 1 Determination of the form factor from SANS profiles for BSA solutions at low ionic strength. Data were taken at station V4, Helmholtz Zentrum Berlin. Only $20 \%$ of data were plotted for clarifying (a) best fit using an oblate form factor, data are shifted for clarity, and (b) comparison of best fits from oblate, prolate and fixed prolate $\left(70 \times 20 \times 20 \AA^{3}\right)$ as form factors.

proposed to possess a cigar-like shape and modeled using a prolate ellipsoid form factor with $R_{a}=70 \AA$ and $R_{b}=20 \AA$. Due to the limited $q$ range in those studies ${ }^{30,32}\left(<0.16 \AA^{-1}\right)$, the model is not sensitive to the difference between prolate and oblate ellipsoid form factor. As seen in Fig. 1b, the differences for these two types of form factor are clearly seen at $q>0.14 \AA^{-1}$. First of all, the prolate form factor decays much faster than that of the oblate. Second, a second scattering maximum would have to be visible at $q=0.28 \AA^{-1}$ (indicated by an arrow for the red and green curves in Fig. 1b), which is not observable from the experimental data and the oblate form factor. The best fit using prolate form factor gives the dimension of $R_{a}=53.9 \AA$ and $R_{b}=21.6 \AA$ in our case. Based on these, we conclude that an oblate ellipsoid form factor is more suitable in our data analysis. Note that we do not intend to describe the details of the shape of protein since a high resolution crystal structure for BSA is not available, but estimate only qualitatively the overall protein geometry. Despite the simplicity, the form factor should give a very good estimate of the volume to be compared to the hydrated volume or dry volume of proteins in solution, in particular since the focus is on relative changes of the volume instead of the aspect ratio of the axis.

Fig. 2a shows SANS data from KWS2 for BSA $9.5 \mathrm{mg} \mathrm{mL}^{-1}$ with $\mathrm{NaCl}$ from low to high ionic strength. The three curves almost overlap indicating the negligible effects of ionic strength on the globular structure of proteins and negligible interactions for these sample solutions. Data from KWS2 give $R_{a}=13.5 \pm 0.6 \AA$ and $R_{b}=41.0 \pm 0.9 \AA$. Data from $\mathrm{D} 22$ give average dimensions of $R_{a}=12.3 \pm 0.8 \AA$ and $R_{b}=42.2 \pm 0.7 \AA$. Fig. $2 \mathrm{~b}$ presents the Kratky plots $\left(I(q) q^{2} \approx q\right)$ of SANS data for samples with $9.5 \mathrm{mg} \mathrm{mL}^{-1}$ BSA and various added salts. The Kratky plot is useful to clarify the folding state of proteins under various conditions. ${ }^{61}$ For compact proteins in 


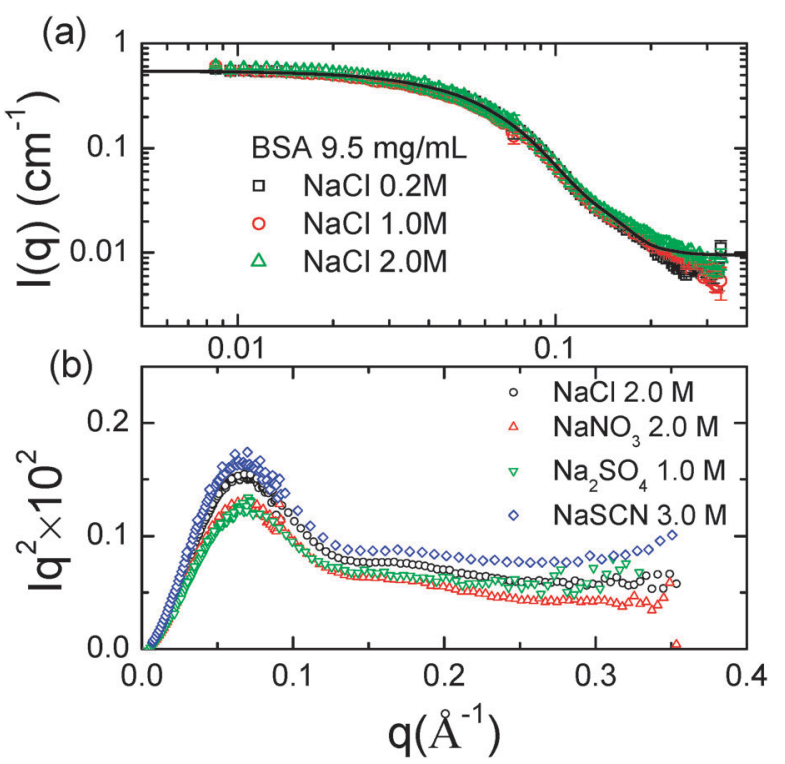

Fig. 2 (a) SANS profiles for BSA solutions with different $\mathrm{NaCl}$ concentration and model fitting using ellipsoid as form factor (data from KWS2). Only $30 \%$ of data points were plotted. (b) Kratky plots of typical SANS data. A well developed bell shape indicates the globular shape of protein without unfolding or denaturation under the concentrated electrolyte solutions.

solution with their native folding state, as described by the Porod law, the scattering intensity decays as $I(q) \approx q^{-4},{ }^{46}$ which in the Kratky plot gives a pronounced peak with a "bell" shape. On the other hand, for completely unfolded proteins, the scattering intensity of biopolymers in a random coil state follows the Debye law, i.e. $I(q) \approx q^{-1}$, which in the Kratky plot shows a steady increase at high $q$ values. ${ }^{61}$ The resulting plots shown in Fig. $2 \mathrm{~b}$ indicate that the addition of salts from both sides of the Hofmeister series does not reduce the compactness of protein significantly, consistent with other studies. ${ }^{3,61-63}$

SANS results collected from different instruments (V4, KWS2, D22) give an averaged dimension of BSA molecule of (12.5 \pm $0.8) \times(41.9 \pm 0.9) \times(41.9 \pm 0.9) \AA^{3}$. Using the maximum error of the axes, we estimate the upper limit for the error of the volume as $\sim 6 \%$, which corresponds to a volume of $91700 \pm 5500 \AA^{3}$. This value is consistent to that reported in the literature, ${ }^{20}$ and close to the volume of HSA determined from the crystal structure $\left(85280 \AA^{3}\right)$ using the PDB file of $1 \mathrm{~N} 5 \mathrm{U}$ and calculated by CRYSOL. ${ }^{64}$ The dry volume of BSA can also be calculated from the specific volume $\left(0.74 \pm 0.02 \mathrm{~cm}^{3} \mathrm{~g}^{-1}\right)^{65}$ divided by $N_{\mathrm{A}}$ and $M_{\mathrm{W}}(66100 \mathrm{Da})$, which gives a value of $81200 \AA^{3}$. SANS measurements thus give a volume about $7.5 \%$ larger than the values calculated from crystal structure of HSA and 13\% larger than that from the specific volume, respectively. This slight enlargement of resulting volume may be partly due to the existence of dimer in BSA solutions. Hunter and Carta analyzed the fraction of dimer and other oligomers in commercial BSA products and found an overall fraction about $6.4 \%$ for the product used in this work. ${ }^{66}$ Dimerization thus cannot be the major contribution to the observed volume increase. In contrast, this dimension is significantly smaller than that determined by SAXS as $17 \times 42 \times 42 \AA^{3}$ with a volume of $125300 \AA^{3}$. Assuming the density increase of the hydrated water is $\sim 10 \%,{ }^{16}$ the hydration level can be calculated

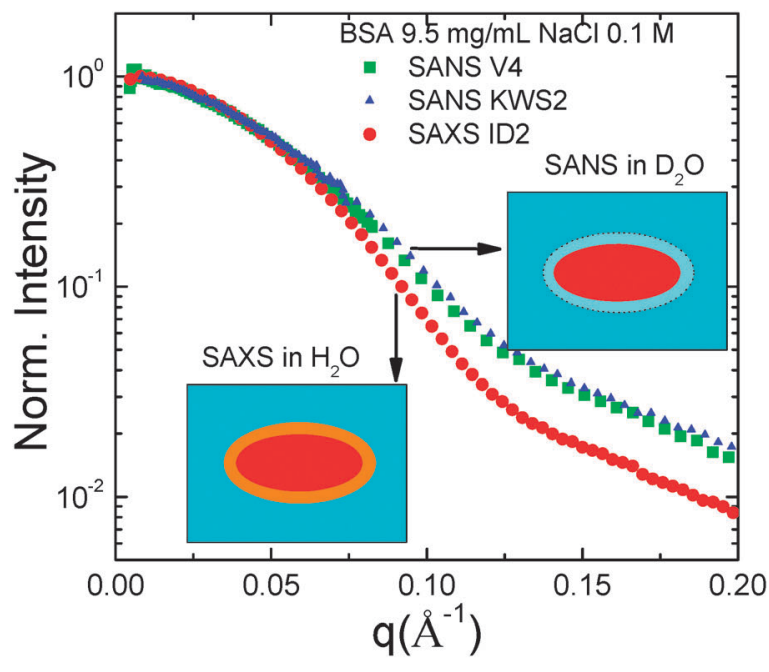

(a)

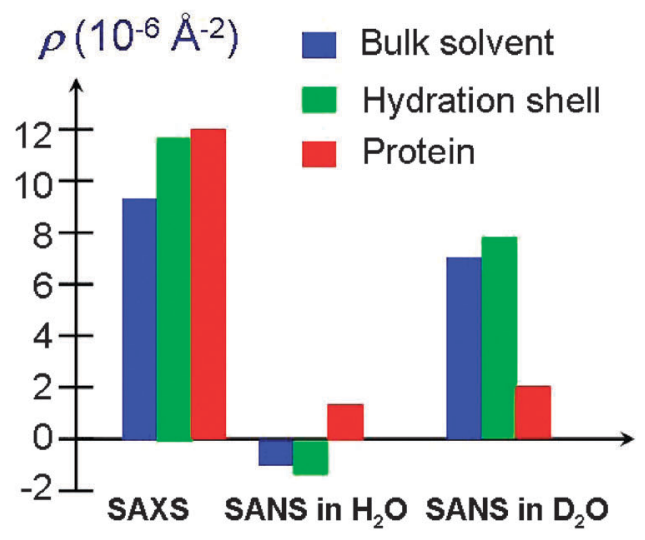

(b)

Fig. 3 (a) Comparison of SANS and SAXS data reveals the effect of the hydration shell. Data are normalized to the forward scattering $I(0)=1$. SAXS data are collected at ESRF, Grenoble. Details can be found in ref. 35. (b) A diagram of SLD explains the contribution of hydration in SANS and SAXS measurements. ${ }^{16}$

by $0.74 \times 36.6 \% \times 1.1 \sim 0.30 \mathrm{~g} \mathrm{~g}^{-1}$ protein for BSA. This hydration level is in good agreement with the values (from 0.3 to $0.4 \mathrm{~g} \mathrm{~g}^{-1} \mathrm{BSA}$ ) reported in the literature. ${ }^{13,30,32,67}$ This hydration effect is clearly seen by comparing the SAXS and SANS profiles on BSA in $\mathrm{H}_{2} \mathrm{O}$ and $\mathrm{D}_{2} \mathrm{O}$ (Fig. 3). A diagram of SLD (Fig. 3b) describes the difference of hydration in SANS and SAXS measurement, which is consistent with literature reports. ${ }^{13,16}$ It is clearly visible that the SANS data shift towards higher $q$ values compared to the SAXS data at $q>0.05 \AA^{-1}$, indicating a shrinkage of the apparent volume of proteins measured by SANS in $\mathrm{D}_{2} \mathrm{O}$. It is worth noting that the shift of SANS data cannot be due to the smearing effect. As discussed in the literature, the major smearing effect of SANS measurement is due to the wavelength spread, $\Delta \lambda / \lambda{ }^{44,53}$ The SANS data from V4 and KWS2 with $\Delta \lambda / \lambda=10 \%$ and $20 \%$, respectively, show very small differences compared to the shift with respect to the SAXS data. Similar behavior has been observed by Svergun et al. ${ }^{16}$

\subsection{Protein-protein interaction from the second virial coefficient}

Fig. 4a presents typical SANS profiles of BSA with $2.0 \mathrm{M}$ $\mathrm{NaNO}_{3}$. A Guinier analysis is used to determine the forward intensity $I(0)$ and radius of gyration, $R_{\mathrm{g}}$, in the $q$ range 

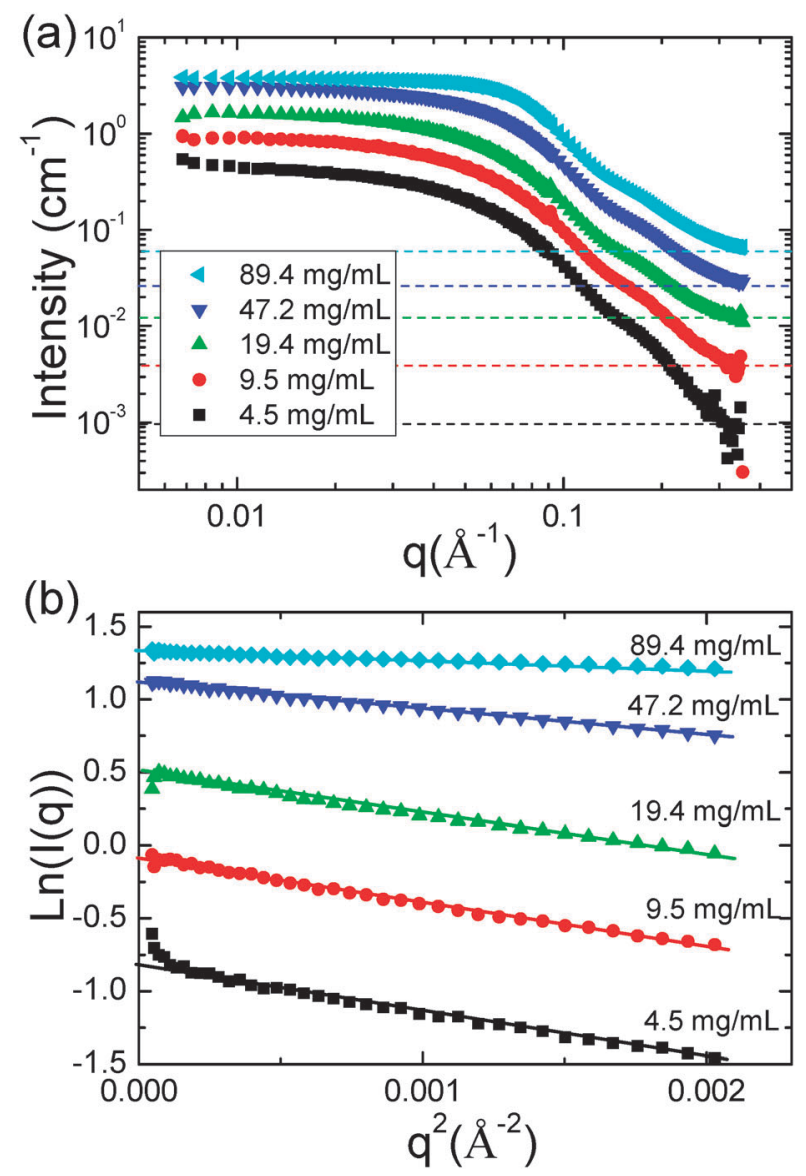

Fig. 4 (a) Representative SANS data (from D22, ILL) for BSA solutions with $\mathrm{NaNO}_{3} 2.0 \mathrm{M}$. The dashed lines correspond to the estimated incoherent background (see text). (b) Guinier plots of SANS data in (a), a good linear relationship was obtained for all samples. $R_{\mathrm{g}}$ and $I(0)$ are obtained from the linear fitting in the $q^{2}$ range of $5 \times 10^{-5}$ to $1.5 \times 10^{-3} \AA^{-2}$.

from 0.005 to $0.045 \AA^{-1}$. Typical Guinier plots (Fig. 4b) show a linear relationship for samples with protein concentration up to $89.4 \mathrm{mg} \mathrm{mL}^{-1}$. Note that the scattering intensity near the beam stop has a higher uncertainty, and the low $q$ upturn (e.g. $4.5 \mathrm{mg} \mathrm{mL}^{-1}$ ) does not happen systematically. Therefore, it is impossible to judge the overall interaction by just looking at the scattering profile in the low $q$ region. Guinier analysis from all samples with low protein concentration $\left(<20 \mathrm{mg} \mathrm{mL}^{-1}\right)$ gives similar values of $R_{\mathrm{g}}=28.7 \pm 1.5 \AA$, which is consistent with the values of 28.7 and $30.5 \AA$ reported in the literature. ${ }^{32,68}$ The molecular weight has been estimated for samples with protein concentration less than $20 \mathrm{mg} \mathrm{mL}^{-1}$. Using an average contrast of $2.73 \times 10^{-6} \AA^{-2}$, we have $168.8 \pm 26.7 \mathrm{kDa}$ (D22, ILL), $83.1 \pm 14.5 \mathrm{kDa}(\mathrm{KWS} 2$, Munich) and $151.9 \pm 15.2 \mathrm{kDa}$ (V4, Berlin). Compared to the theoretical value of the BSA monomer $(66.1 \mathrm{kDa})$, a factor of 2 may prevail for values from different instruments. Note that the samples have been prepared always in the same way. However, the average error is larger than $10 \%$ in any case, therefore, we did not use these values for further analysis.

The forward intensity, $I(0)$, is used to calculate $A_{2}$ according to eqn (7). In the case of the SANS data analysis, the incoherent background has to be subtracted from the forward intensity.
The background is determined using the Porod law. ${ }^{46}$ By plotting $I(q) q^{4}$ vs. $q^{4}$, the slope of the linear relationship gives the incoherent background. ${ }^{46}$ As indicated in Fig. 4a, the constant backgrounds for BSA 4.5, 9.5, 19.5, 47.2 and $89.4 \mathrm{mg} \mathrm{mL}^{-1}$ with $2.0 \mathrm{M} \mathrm{NaNO}_{3}$ are 0.0004, 0.002, 0.010, 0.023 and $0.055 \mathrm{~cm}^{-1}$, respectively. Compared to the forward intensity, the background contributes about $0.5-2 \%$. It is important to correct for it. For example, without background correction, $A_{2}$ for this condition would be $1.41 \times 10^{-4} \mathrm{~mol} \mathrm{~mL} \mathrm{~g}{ }^{-2}$, however after background correction, $A_{2}=1.45 \times 10^{-4} \mathrm{~mol} \mathrm{~mL} \mathrm{~g}{ }^{-2}$. Fig. 5a displays the typical plots of $c /(I(0)-\mathrm{B})$ versus $c$ for protein solutions with various salts and ionic strength. In all of these, a good linear relationship is obtained. The factor $\alpha$ is constant for each series of samples where only protein concentrations are varied and the salt concentrations are kept constant. From the intercept and the slope of the linear fit, $A_{2}$ values are determined and listed in Table 1 and presented in Fig. 5b. In all cases, $A_{2}>0$, indicating the repulsive nature of the effective interactions under the present experimental conditions. This is consistent with the fact that all solutions are stable during the experiments. As displayed in Fig. 5b, the effect of added salt on the protein interactions is clearly visible. The $A_{2}$ follows the inverse Hofmeister series, $\left(\mathrm{NH}_{4}\right)_{2} \mathrm{SO}_{4}<\mathrm{Na}_{2} \mathrm{SO}_{4}<\mathrm{NaOAc}<\mathrm{NaCl}<\mathrm{NaNO}_{3}<\mathrm{NaSCN}$. This effect, namely that protein interaction in solution follows the inverse order of the Hofmeister series, has been observed in several protein systems, such as lysozyme, $\alpha$ - and $\gamma$-crystallins. ${ }^{48,50,51,69}$ Using SAXS, Bonneté et al. studied the effective protein-protein interactions in lysozyme solutions as a function of temperature, ionic strength and salt type. ${ }^{48,49,51}$ $A_{2}$ for various conditions from under-saturated to supersaturated solutions were determined from the structure factor. The addition of salt can induce an additional attractive potential
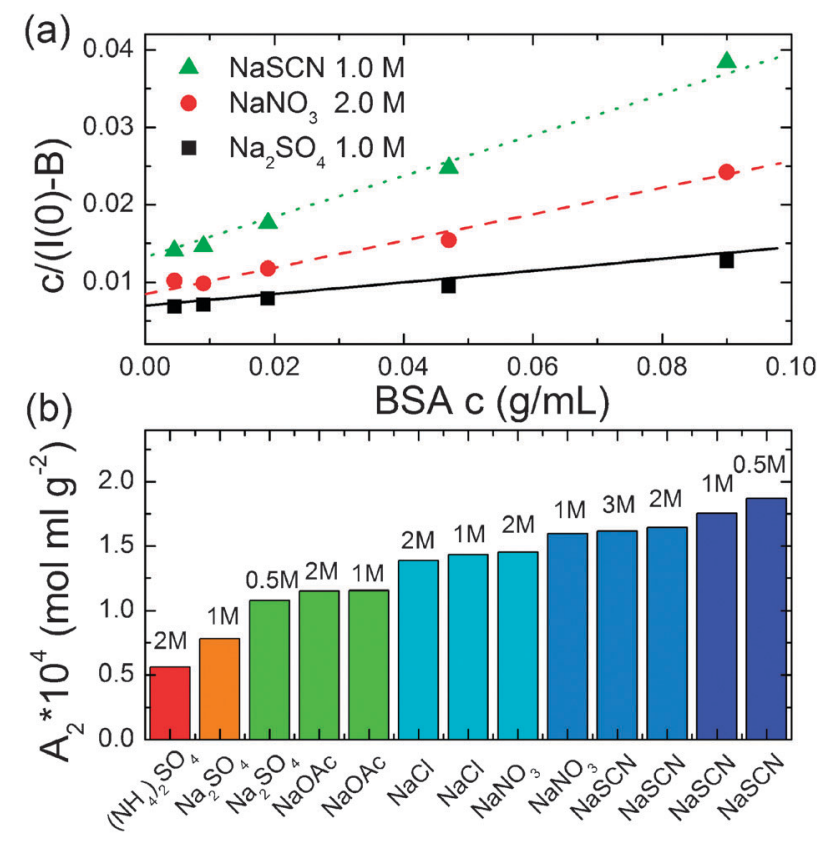

Fig. 5 (a) Plots of $c /(I(0)-\mathrm{B})$ as a function of protein concentration. The intercept and the slope of linear fitting are used to determine the second virial coefficient, $A_{2}$, according to eqn (7). (b) Presentation of $A_{2}$ with various salts in the increase trend. The effect of the type of salts follows the Hofmeister series. 
Table 1 The second virial coefficient, $A_{2}$ and $B_{2}$, of BSA in various salt solutions, $B_{2}$ is calculated with different approaches as described in the text

\begin{tabular}{|c|c|c|c|c|c|c|c|c|}
\hline \multirow[t]{2}{*}{ Salt concentration/M } & \multirow[t]{2}{*}{ Station } & \multirow[t]{2}{*}{$A_{2}\left(10^{-4} \mathrm{~mol} \mathrm{~mL} \mathrm{g_{-2 }}\right)$} & \multicolumn{6}{|c|}{$B_{2}$} \\
\hline & & & $v$ & SANS & SANS + Isihara & $v+$ hydration & SAXS & SAXS + Isihara \\
\hline & & & $81200^{a}$ & $91700^{a}$ & $134700^{a}$ & $114500^{a}$ & $125300^{a}$ & $157500^{a}$ \\
\hline$\left(\mathrm{NH}_{4}\right)_{2} \mathrm{SO}_{4} 1.5 \mathrm{M}$ & KWS2 & $0.55 \pm 0.16$ & 4.9 & 4.4 & 3.0 & 3.5 & 3.2 & 2.5 \\
\hline $\mathrm{Na}_{2} \mathrm{SO}_{4} 0.5 \mathrm{M}$ & D22 & $1.06 \pm 0.05$ & 9.5 & 8.4 & 5.7 & 6.7 & 6.1 & 4.9 \\
\hline $\mathrm{Na}_{2} \mathrm{SO}_{4} 1.0 \mathrm{M}$ & D22 & $0.77 \pm 0.03$ & 6.9 & 6.1 & 4.2 & 4.9 & 4.5 & 3.6 \\
\hline $\mathrm{NaOAc} 1.0 \mathrm{M}$ & D22 & $1.14 \pm 0.11$ & 10.2 & 9.0 & 6.1 & 7.2 & 6.6 & 5.3 \\
\hline $\mathrm{NaOAc} 2.0 \mathrm{M}$ & D22 & $1.12 \pm 0.09$ & 10.0 & 8.9 & 6.1 & 7.1 & 6.5 & 5.2 \\
\hline $\mathrm{NaCl} 1.0 \mathrm{M}$ & D22 & $1.40 \pm 0.07$ & 12.5 & 11.1 & 7.6 & 8.9 & 8.1 & 6.5 \\
\hline $\mathrm{NaCl} 2.0 \mathrm{M}$ & D22 & $1.37 \pm 0.09$ & 12.2 & 10.8 & 7.4 & 8.7 & 7.9 & 6.3 \\
\hline $\mathrm{NaNO}_{3} 1.0 \mathrm{M}$ & D22 & $1.56 \pm 0.12$ & 14.0 & 12.4 & 8.4 & 9.9 & 9.0 & 7.2 \\
\hline $\mathrm{NaNO}_{3} 2.0 \mathrm{M}$ & D22 & $1.45 \pm 0.06$ & 12.9 & 11.4 & 7.8 & 9.2 & 8.4 & 6.7 \\
\hline NaSCN $0.5 \mathrm{M}$ & KWS2 & $1.91 \pm 0.05$ & 17.0 & 15.1 & 10.3 & 12.1 & 11.0 & 8.8 \\
\hline $\mathrm{NaSCN} 1.0 \mathrm{M}$ & KWS2 & $1.79 \pm 0.08$ & 16.0 & 14.2 & 9.7 & 11.4 & 10.4 & 8.3 \\
\hline NaSCN $2.0 \mathrm{M}$ & KWS2 & $1.67 \pm 0.04$ & 15.0 & 13.2 & 9.0 & 10.6 & 9.7 & 7.7 \\
\hline NaSCN $3.0 \mathrm{M}$ & KWS2 & $1.66 \pm 0.09$ & 14.9 & 13.2 & 9.0 & 10.5 & 9.6 & 7.7 \\
\hline
\end{tabular}

that is a function of the anion type and follows the order of the Hofmeister series. The order is direct or reverse when the $\mathrm{pH}$ values of the solutions are above or below the $\mathrm{pI}$ of proteins, respectively. ${ }^{51}$ A value of $A_{2}=1 \times 10^{-4} \mathrm{~mol} \mathrm{~mL} \mathrm{~g}^{-2}$ has been reported by Tessier et al. for BSA solutions with $\mathrm{NaCl}$ at neutral $\mathrm{pH}^{70}$ A similar value is reported by Vilker et al. as $A_{2}=1.34 \times 10^{-4} \mathrm{~mol} \mathrm{~mL} \mathrm{~g}{ }^{-2}$ for BSA with $150 \mathrm{mM}$ $\mathrm{NaCl}^{71}$ These values are in good agreement with our measurements by SANS (Table 1). With 1.0 and $2.0 \mathrm{M} \mathrm{NaCl}$, the $A_{2}$ are 1.40 and $1.37 \times 10^{-4} \mathrm{~mol} \mathrm{~mL} \mathrm{~g}{ }^{-2}$, respectively.

$A_{2}$ has been proposed to be the indicator for optimizing the conditions of protein crystallization. George and Wilson proposed that the best condition for protein crystallization corresponds to a narrow range of $A_{2}$, from -1.0 to $-8.0 \times 10^{-4} \mathrm{~mol} \mathrm{~mL} \mathrm{~g}^{-2}{ }^{72}$ Bonneté and Vivarés studied the crystallization conditions of different biological macromolecules with molecular weight from $14 \mathrm{kDa}$ to $4600 \mathrm{kDa}^{49}$ It was found that for large macromolecules, the $A_{2}$ values are slightly positive, but smaller than those of the corresponding hard-spheres, indicating an attraction in addition to the hard-sphere repulsion. The dimensionless second virial coefficient $B_{2}=M_{\mathrm{w}} A_{2} / v=A_{2} M_{\mathrm{w}}{ }^{2} / \mathrm{V} / N_{\mathrm{A}}$, which is rescaled from experimental to theoretical units by the molecular weight and corrected for the excluded volume $V$ of a single particle, is suggested to be a better indicator for good protein crystallization conditions, because it depends only on the nature and the relative strength of the pair interaction potential and not on the molecular size. ${ }^{73}$ From the definition of $B_{2}$, the effective interaction between protein molecules becomes attractive for $B_{2}<4$ and repulsive for $B_{2}>4$.

However, the calculation of $B_{2}=M_{\mathrm{w}} A_{2} / v=A_{2} M_{\mathrm{w}}{ }^{2} /\left(\mathrm{V} / N_{\mathrm{A}}\right)$ depends on the choice of the volume, in particular whether the hydration shell and the non-spherical shape are taken into account. In principle, the volume can be calculated from the well-known specific volume of the protein, $V_{\text {bare }}{ }^{(\text {th })}=0.74 \mathrm{~cm}^{3} \mathrm{~g}^{-1} M_{\mathrm{w}} / N_{\mathrm{A}}$, also including the hydration shell (assuming a $0.3 \mathrm{~g} \mathrm{~g}^{-1}$ hydration level), $V_{\text {hydr }}{ }^{\text {(th) }}=(0.74+0.3) \mathrm{cm}^{3} \mathrm{~g}^{-1} M_{\mathrm{w}} / N_{\mathrm{A}}$. The ellipsoidal shape determined from SANS and SAXS experiments can be used to calculate the bare volume (SANS), $V_{\text {bare }}{ }^{(\exp )}=4 \pi / 3 \times$ $12.5 \times 41.9 \times 41.9 \AA^{3}$, and hydrated volume (SAXS), $V_{\text {hydr }}{ }^{(\exp )}=4 \pi / 3 \times 17 \times 42 \times 42 \AA^{3}$. Importantly, for a hard ellipsoid, the second virial coefficient $B_{2}$ does not only depend on the size but also on the aspect ratio. This effect of nonspherical shape can be accounted for with an effective sphere with the Isihara radius (see Methods section). Thus, we can calculate the volumes of these Isihara spheres for the experimentally determined ellipsoids, obtaining $V_{\text {bare }}{ }^{\text {(Isihara) }}=4 \pi / 3 \times(31.8 \AA)^{3}$ and $V_{\text {hydr }}$ (Isihara) $=4 \pi / 3 \times(33.5 \AA)^{3}$. We summarize the different volumes and the obtained $B_{2}$ values in Table 1 .

Obviously, different volumes simply correspond to a scaling factor for the virial coefficient. This scaling behavior, however, can induce mis-interpretation of the qualitative nature of the underlying interaction. Reconsidering that the excluded volume contribution is represented with $B_{2}=4$, a small factor can change the interpretation from a hard sphere with additional repulsion to one with additional attraction. Indeed, this case is observed for samples with $1.5 \mathrm{M}\left(\mathrm{NH}_{4}\right)_{2} \mathrm{SO}_{4}$, where the virial coefficient changes from $B_{2}=4.9$ for the bare protein volume, i.e. additional repulsion, to $B_{2}=3.5$ for the hydrated protein volume, i.e. additional attraction. When considering the nonspherical shape, the values get even smaller, suggesting a stronger attraction.

For our measurements, the virial coefficients generally follow the expected relative order from the Hofmeister series for each of the six approaches. In particular, for salting-in salts, all calculated absolute values for $B_{2}$ correspond to a stronger repulsion than only the excluded volume. For salting-out conditions like $\left(\mathrm{NH}_{4}\right)_{2} \mathrm{SO}_{4} 1.5 \mathrm{M}, \mathrm{Na}_{2} \mathrm{SO}_{4} 1.0 \mathrm{M}$ or $\mathrm{NaOAc}$ $2.0 \mathrm{M}$, we expect an additional attraction or at least an interaction close to the excluded volume case. This expectation corresponds to $B_{2} \leq 4$ and is only found if hydration, nonspherical shape or both are taken into account. Unfortunately, these two contributions are not as well-defined as the bare protein volume. The real protein shape differs from the ellipsoid of revolution and is hard to predict. Surface roughness has been shown to increase the excluded volume considerably. ${ }^{74-76}$ For example, Neal and Lenhoff found that the excluded volume is about 6.7 times the molecular volume from the crystallographic structure instead of 4 times for a smooth sphere. ${ }^{77}$ This result is comparable with our calculation using the volume from SAXS. However, the hydration shell is not a uniform layer of increased water density, and the hydration level can change due to salt conditions and temperature. ${ }^{78}$ A precise description of the 
excluded volume contribution to the second virial coefficient is difficult and the use of $A_{2}$ or $B_{2}$ to describe the effective interaction between particles should be interpreted with care, in particular when the interactions are weak.

\subsection{Experimental structure factor and effective protein-protein interactions from model fitting}

For BSA in $\mathrm{D}_{2} \mathrm{O}$, assuming no $\mathrm{H}-\mathrm{D}$ exchange, the scattering length density (SLD) would be about $1.84 \times 10^{-6} \AA^{-2}$. However, there are 1018 exchangeable hydrogens in one BSA molecule and up to $90 \%$ of them can be exchanged after $24 \mathrm{~h},{ }^{79}$ which corresponds to a SLD of $3.04 \times 10^{-6} \AA^{-2}$. In practice, the $\mathrm{H}-\mathrm{D}$ exchange depends on protein concentration. ${ }^{30} \mathrm{By}$ considering $70 \%$ exchange, the SLD is $2.77 \times 10^{-6} \AA^{-2}$, which is close to the fitted value. For example, from the data with 4.9 and $89.4 \mathrm{mg} \mathrm{mL}^{-1}$ BSA with $0.1 \mathrm{M} \mathrm{NaCl}$ collected at D22 (Fig. 6a), when fixing the solvent SLD $\left(\mathrm{D}_{2} \mathrm{O}, 6.34 \times 10^{-6} \AA^{-2}\right)$, we get SLD of BSA of 2.71 and $2.87 \times 10^{-6} \AA^{-2}$, respectively. These values are consistent to those reported in the literature. ${ }^{30}$ Since the difference of SLD between protein and solvent contributes to a constant factor of data fitting, for the remaining data fitting, we fix the SLD of the protein to $2.70 \times 10^{-6} \AA^{-2}$.

Fig. 6a presents the full $q$-range SANS data with simulated data derived from the model. With low ionic strength, SANS data for higher protein concentrations, the interaction can be well described using a screened Coulomb potential in the structure factor. The fit parameters are listed in Table 2. For BSA 47.2 and $89.4 \mathrm{mg} \mathrm{mL}^{-1}$, the experimental volume fractions are $3.49 \%$ and $6.62 \%$, respectively. The fitted volume fraction values are systematically higher and the surface charges are 16 to $20 e$. These results are in good agreement with our previous study using SAXS as well as those reported in the literature. ${ }^{20,36}$ It is interesting to see that for $0.5 \mathrm{M} \mathrm{NaSCN}$, the data with $89.4 \mathrm{mg} \mathrm{mL}^{-1}$ BSA are better described using a screened Coulomb potential, indicating that the surface charge still plays a role. The higher surface charge $(36.6 e)$ can be explained by the strong salting-in effect of the thiocyanate anion. Studies have shown that $\mathrm{SCN}^{-}$can strongly adsorb onto serum albumin. As many as $40 \mathrm{SCN}^{-}$ions can be bound to each albumin molecule. ${ }^{80,81}$ With high salt concentration $(>0.5 \mathrm{M})$, the SANS data are best described using form factor plus a hard sphere structure factor. Fig. $6 \mathrm{~b}$ shows typical SANS data along with model fitting using a hard sphere potential in the presence of NaSCN. The only fitting parameter is the volume fraction of protein in the solutions. As listed in Table 3, the obtained volume fractions are generally higher than the experimental values. This is consistent since the fitted volume fraction is based on effective spheres with the Isihara radius.

When salting-out salts were added, such as $\mathrm{Na}_{2} \mathrm{SO}_{4}$ and $\left(\mathrm{NH}_{4}\right)_{2} \mathrm{SO}_{4}$, the SANS data of course cannot be understood using a hard sphere potential (Fig. 6c). Using the free volume and the SLD of protein as the fit parameters, the resulting volume fraction and the SLD values are too low (Table 3), i.e. SLD $<1.84 \times 10^{-6} \AA^{-2}$. When fixing the volume fraction, one finds that the model calculated profiles deviate significantly from the SANS data in the low $q$ region (Fig. 6c). This deviation is also observed for samples with $\left(\mathrm{NH}_{4}\right)_{2} \mathrm{SO}_{4}$. The steady
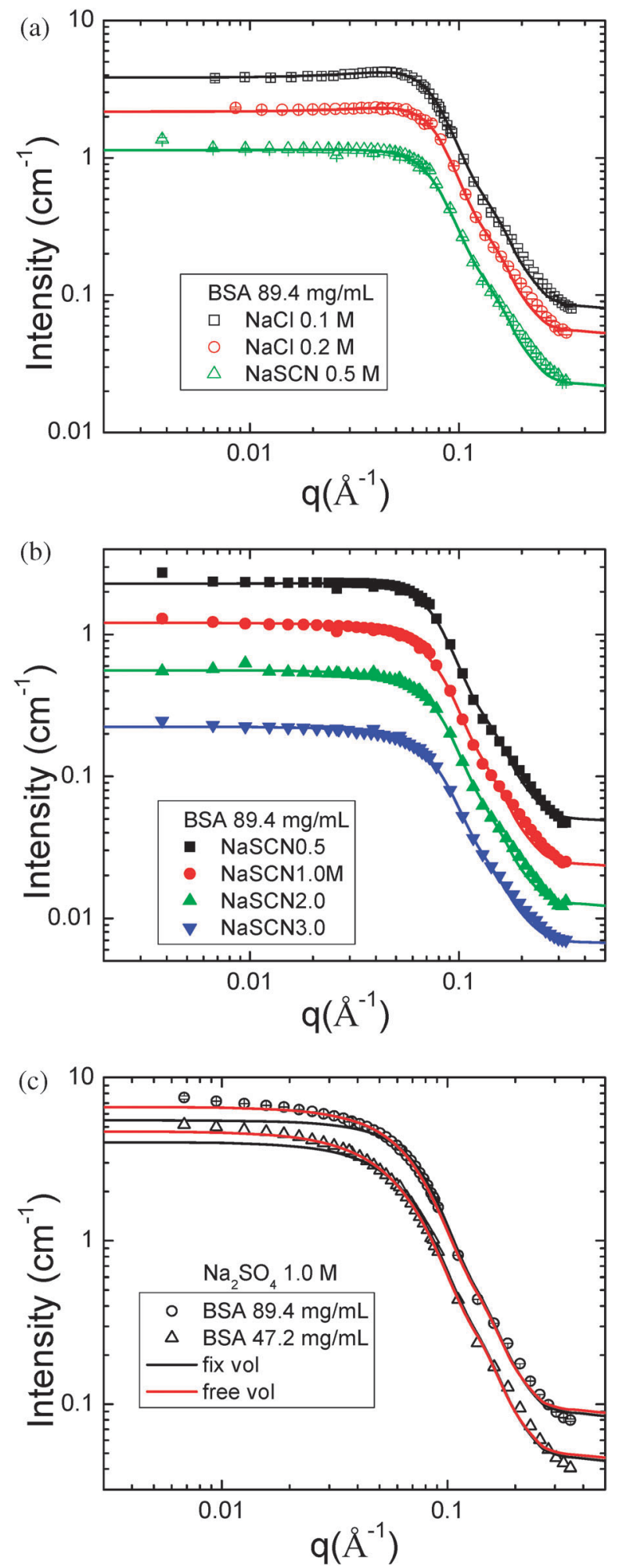

Fig. 6 SANS data with model fitting: (a) BSA with $\mathrm{NaCl}(0.1$ and $0.2 \mathrm{M})$ and NaSCN $(0.5 \mathrm{M})$. (b) Typical SANS data with model fitting for BSA $89.4 \mathrm{mg} \mathrm{mL}^{-1}$ with concentrated NaSCN (data from KWS2). (c) SANS data with model fitting for BSA with $\mathrm{Na}_{2} \mathrm{SO}_{4}$ indicate significant deviation from the hard sphere potential (see text). In all plots, only $30 \%$ of data points were plotted.

increase of scattering intensity in the low $q$ region might be due to the appearance of an attractive potential. These results 
Table 2 Fitting parameters for sample solutions with a low ionic strength ${ }^{a}$

\begin{tabular}{lllll}
\hline Samples & Fitted volume $(\%)$ & Fixed ionic strength/M & SLD solvent $\left(\times 10^{-6} \AA^{-2}\right)$ & Effective Surface charges $(\mathrm{e})$ \\
\hline BSA47.2 NaCl 0.1 M & 5.75 & 0.1 & 6.32 & 17.0 \\
BSA89.4 NaCl 0.1 M & 7.82 & 0.1 & 6.32 & 16.6 \\
BSA47.2 NaCl 0.2 M & 4.37 & 0.2 & 5.35 & 18.6 \\
BSA89.4 NaCl 0.2 M & 9.22 & 0.2 & 5.27 & 21.5 \\
BSA89.4 NaSCN 0.5 M & 7.08 & 0.5 & 5.42 & 36.6
\end{tabular}

${ }^{a}$ The errors of the parameters pertaining to the fitting procedure are better than $5 \%$, but the systematic errors, including sample preparation, raw data reduction, and calibration, are estimated to $\sim 10 \%$. The same condition applies to Table 3 .

Table 3 Fitting parameters for sample solutions with a high ionic strength

\begin{tabular}{llll}
\hline BSA 47.2/89.4 mg mL & $\begin{array}{l}\text { Fitted } \\
\text { volume }(\%)\end{array}$ & $\begin{array}{l}\text { SLD solvent } \\
\left(\times 10^{-6} \AA^{-2}\right)\end{array}$ & $\begin{array}{l}\text { SLD protein } \\
\left(\times 10^{-6} \AA^{-2}\right)\end{array}$ \\
\hline $\mathrm{NaCl} \mathrm{1.0} \mathrm{M}$ & $4.78 / 9.97$ & $5.23 / 5.12$ & 2.70 \\
$\mathrm{NaCl} 2.0 \mathrm{M}$ & $4.68 / 10.1$ & $5.22 / 5.14$ & 2.70 \\
$\mathrm{NaNO}_{3} 1.0 \mathrm{M}$ & $3.80 / 8.84$ & $6.40 / 6.06$ & 2.70 \\
$\mathrm{NaNO}_{3} 2.0 \mathrm{M}$ & $3.53 / 8.86$ & $6.16 / 5.73$ & 2.70 \\
$\mathrm{NaOAc} 1.0 \mathrm{M}$ & $3.28 / 7.87$ & $6.29 / 5.82$ & 2.70 \\
$\mathrm{NaOAc} 2.0 \mathrm{M}$ & $3.58 / 8.07$ & $5.24 / 4.96$ & 2.70 \\
$\mathrm{NaSCN} 0.5 \mathrm{M}$ & 3.48 & 5.43 & 2.70 \\
$\mathrm{NaSCN} 1.0 \mathrm{M}$ & $3.63 / 8.54$ & $5.39 / 5.13$ & 2.70 \\
$\mathrm{NaSCN}_{2} .0 \mathrm{M}$ & $3.72 / 9.47$ & $5.18 / 5.00$ & 2.70 \\
$\mathrm{NaSCN} 3.0 \mathrm{M}_{\mathrm{Na}_{2} \mathrm{SO}_{4} 1.0 \mathrm{M}}$ & $3.79 / 9.42$ & $4.95 / 4.74$ & 2.70 \\
$\mathrm{Na}_{2} \mathrm{SO}_{4} 1.0 \mathrm{M}$ & $1.49 / 4.73$ & $6.34 \mathrm{fix}$ & $1.78 / 1.67$ \\
\hline & $4.00 / 8.00 \mathrm{fix}$ & $6.34 \mathrm{fix}$ & $2.49 / 2.63$ \\
\hline
\end{tabular}

are consistent with the observation of the previously discussed smaller second virial coefficient in salting-out conditions. For $B_{2}<4$, an additional attractive interaction is expected, which obviously cannot be reproduced with the repulsive hard sphere potential.

This scenario is further confirmed by the experimental structure factor (Fig. 7), which is determined by dividing the

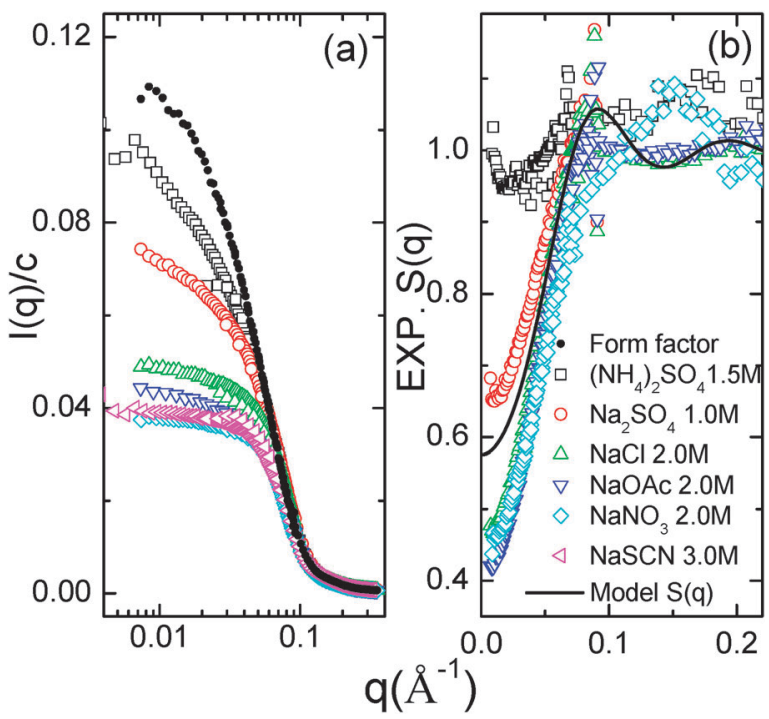

Fig. 7 (a) A comparison of SANS data for BSA $89.4 \mathrm{mg} \mathrm{mL}^{-1}$ with various salts with the experimental form factor from BSA $9.5 \mathrm{mg} \mathrm{mL}^{-1}$ with $\mathrm{NaCl}$ 1.0 M. All data have been corrected for protein concentration. (b) Experimental structure factor from (a). The solid line is the theoretical curve of $S(q)$ of a hard sphere potential with an effective diameter of $63.5 \AA$ and a volume fraction of $7.0 \%$ for comparison.
SANS data by the form factor directly. The normalized SANS data were plotted together with an experimental form factor (with BSA $9.5 \mathrm{mg} \mathrm{mL}^{-1}$ and $\mathrm{NaCl} 1.0 \mathrm{M}$ ) (Fig. 7a). It is obvious that all the samples in the low $q$ region $\left(<0.05 \AA^{-1}\right)$ have lower intensity compared to that of the form factor, indicating a weak repulsion. Experimental structure factors are shown in Fig. 7b. For comparison, a hard sphere structure factor was calculated using the Isihara radius of $31.8 \AA$ and a volume fraction of $7 \%$. The hard sphere potential is used here to monitor the subtle changes on potentials upon addition of different salts. Comparing with the model curve in the low $q$ region, one sees that with $\mathrm{Na}_{2} \mathrm{SO}_{4}$ and $\left(\mathrm{NH}_{4}\right)_{2} \mathrm{SO}_{4}$, the low $q$ values are higher than the model value, which indicates attraction, but the overall values of $S(q)$ in the low $q$ region are still smaller than unity. Comparing with the previous section, we note that the second virial coefficient with correction for the non-spherical shape of proteins using the Isihara radius describes the interactions better than that determined from the bare protein. By comparing different salts, one can observe the consistent results of the Hofmeister effect as observed in other protein systems. ${ }^{48,51}$

\section{Conclusions}

In this work, we have reported a SANS study on the hydration and protein interactions in solution containing concentrated electrolytes. The data are also compared with a previous study using SAXS. ${ }^{36}$ SANS measurements from three stations (D22, KWS2 and V4) give very consistent results: first, the form factors $P(q)$ extracted from dilute protein solutions give an averaged dimension of BSA of $12.5 \times 42 \times 42 \AA^{3}$, corresponding to a volume of $91700 \AA^{3}$ which is about $7.5 \%$ and $13 \%$ larger than the values calculated from crystal structure of HSA and the specific volume of BSA, respectively. This dimension is significantly smaller than that determined by SAXS as $17 \times 42 \times 42 \AA^{3}$ with a volume of $125300 \AA^{3}$. The difference in volume (37\%) supports the idea of the contribution of a hydration shell with a hydration level of $\sim 0.30 \mathrm{~g} \mathrm{~g}^{-1}$ protein. These results indicate that compared to SAXS, the SANS measurements are not sensitive to the $\sim 10 \%$ density difference between the hydrated and bulk water due to the small thickness of this hydration shell $(\sim 3 \AA)$, which makes a combination of SANS and SAXS an ideal tool to study the hydration effect in protein solutions under various conditions.

Second, the effective protein-protein interactions in solutions containing concentrated salts can be described using the second virial coefficient, $A_{2}$, and its dependence on the nature of the added salts is clearly visible. It is found that $A_{2}$ follows the 
reverse order of the Hofmeister series, i.e. $\left(\mathrm{NH}_{4}\right)_{2} \mathrm{SO}_{4}<$ $\mathrm{Na}_{2} \mathrm{SO}_{4}<\mathrm{NaOAc}<\mathrm{NaCl}<\mathrm{NaNO}_{3}<\mathrm{NaSCN}$. The calculation of the dimensionless second virial coefficient $B_{2}$ reveals that the hydration and the non-spherical shape of proteins have to be considered for a better description of interactions in protein solutions with concentrated electrolytes. SANS data are further analyzed using the full $q$-range based on liquid theoretical approaches, confirming the results of experimental structure factor and the $A_{2}$ analysis. Consistently, the additional interaction on top of the hard sphere repulsion is found to change from repulsive for salting-in conditions to attractive for salting-out conditions.

\section{Acknowledgements}

We gratefully acknowledge financial support from Deutsche Forschungsgemeinschaft (DFG) and the beam time allocation from ESRF, ILL, JCNS and Helmholtz-Center Berlin (BENSC). The beam time on V4 at the Helmholtz Zentrum Berlin has been supported by the European Commission under the 6th Framework Program through the Key Action: Strengthening the European Research Area, Research Infrastructures. Contract No. RII3-CT-2003-505925 (NMI3).

\section{Notes and references}

1 R. A. Curtis, H. W. Blanch and J. M. Prausnitz, J. Phys. Chem. B, 2001, 105, 2445-2452.

2 R. A. Curtis, J. M. Prausnitz and H. W. Blanch, Biotechnol. Bioeng., 1998, 57, 11-21.

3 R. A. Curtis, J. Ulrich, A. Montaser, J. M. Prausnitz and H. W. Blanch, Biotechnol. Bioeng., 2002, 79, 367-380.

4 S. D. Durbin and G. Feher, Annu. Rev. Phys. Chem., 1996, 47, 171-204.

5 R. Piazza, Curr. Opin. Colloid Interface Sci., 2000, 5, 38-43.

6 R. Piazza, Curr. Opin. Colloid Interface Sci., 2004, 8, 515-522.

7 K. D. Colloins, Methods, 2004, 34, 300-311.

8 K. D. Colloins and M. W. Q. Washabaugh, Q. Rev. Biophys., 1985, 18, 323-421.

9 K. D. Colloins, Biophys. J., 1997, 72, 65-76.

10 B. Jacrot, Rep. Prog. Phys., 1976, 39, 911-953.

11 B. Jacrot and G. Zaccai, Biopolymers, 1981, 20, 2413-2426.

12 J. Lipfert and S. Doniach, Annu. Rev. Biophys. Biomol. Struct., 2007, 36, 307-327.

13 S. J. Perkins, Biophys. Chem., 2001, 93, 129-139.

14 S. J. Perkins, A. I. Okemefuna, A. N. Fernando, A. Bonner, H. E. Gilbert and P. B. Furtado, Methods Cell Biol., 2008, 84, 376-423.

15 M. V. Petoukhov and D. I. Svergun, Eur. Biophys. J., 2006, 35, 567-576.

16 D. I. Svergun, S. Richard, M. H. J. Koch, Z. Sayers, S. Kuprin and G. Zaccai, Proc. Natl. Acad. Sci. U. S. A., 1998, 95, 2267-2272.

17 A. Stradner, F. Cardinaux and P. Schurtenberger, J. Phys. Chem. B, 2006, 110, 21222-21231.

18 A. Stradner, H. Sedgwick, F. Cardinaux, W. C. K. Poon, S. U. Egelhaaf and P. Schurtenberger, Nature, 2004, 432, 492-495.

19 R. Sinibaldi, J. Chem. Phys., 2007, 126, 235101.

20 R. Sinibaldi, M. Ortore, F. Spinozzi, S. de Souza Funari, J. Teixeira and P. Mariani, Eur. Biophys. J., 2008, 37, 673-681.

21 G. Zaccai and B. Jacrot, Annu. Rev. Biophys. Bioeng., 1983, 12, 139-157.

22 F. Merzel and J. Smith, Proc. Natl. Acad. Sci. U. S. A., 2002, 99, $5378-5383$.

23 F. Hofmeister, Arch. Exp. Pathol. Pharmakol., 1888, 24, 247-260.

24 R. L. Baldwin, Biophys. J., 1996, 71, 2056-2063.

25 A. Dér, L. Kelemen, L. Fábián, S. G. Taneva, E. Fodor, T. Páli, A. Cupane, M. G. Cacace and J. J. Ramsden, J. Phys. Chem. B, 2007, 111, 5344-5350.
26 B. W. Ninham and P. Lo Nostro, Molecular Forces and Self Assembly, Cambridge University Press, New York, 2010.

27 Y. Levin, Phys. Rev. Lett., 2009, 102, 147803.

28 N. Schwierz, D. Horinek and R. R. Netz, Langmuir, 2010, 26, 7370-7379.

29 L. R. S. Barbosa, M. G. Ortore, F. Spinozzi, P. Mariani, S. Bernstorff and R. Itri, Biophys. J., 2010, 98, 147-157.

30 R. Nossal, C. J. Glinka and S. H. Chen, Biopolymers, 1986, 25 $1157-1175$.

31 M. Kotlarchyk and S. H. Chen, J. Chem. Phys., 1983, 79, 2461-2469.

32 D. Bendedouch and S. H. Chen, J. Phys. Chem., 1983, 87, 1473-1477.

33 D. Bendedouch, S. H. Chen and W. C. Koehler, J. Phys. Chem., 1983, 87, 2621-2628.

34 F. Roosen-Runge, M. Hennig, T. Seydel, F. Zhang, M. W. A. Skoda, S. Zorn, R. M. J. Jacobs, M. Maccarini, P. Fouquet and F. Schreiber, Biochim. Biophys. Acta, 2010, 1804, 68-75.

35 F. Roosen-Runge, M. Hennig, F. Zhang, R. M. J. Jacobs, M. Sztucki, H. Schober, T. Seydel and F. Schreiber, Proc. Natl. Acad. Sci. U. S. A., 2011, 108, 11815-11820.

36 F. Zhang, M. W. A. Skoda, R. M. J. Jacobs, R. A. Martin, C. M. Martin and F. Schreiber, J. Phys. Chem. B, 2007, 111, 251-259.

37 F. Zhang, M. W. A. Skoda, R. M. J. Jacobs, S. Zorn, R. A. Martin, C. M. Martin, G. F. Clark, S. Weggler, A. Hildebrandt, O. Kohlbacher and F. Schreiber, Phys. Rev. Lett., 2008, 101, 148101.

38 L. Ianeselli, F. Zhang, M. W. A. Skoda, R. M. J. Jacobs, R. A. Martin, S. Callow, S. Prévost and F. Schreiber, J. Phys. Chem. B, 2010, 114, 3776-3783.

39 F. Zhang, S. Weggler, M. Ziller, L. Ianeselli, B. S. Heck, A. Hildebrandt, O. Kohlbacher, M. W. A. Skoda, R. M. J Jacobs and F. Schreiber, Proteins: Struct., Funct., Bioinf., 2010, 78, 3450-3457.

40 GRASP, http://www.ill.fr/lss/grasp/grasp_main.html.

41 U. Keiderling and A. Wiedenmann, Physica B (Amsterdam), 1995, 213-214, 895-897.

42 U. Keiderling, Appl. Phys. A: Solid Surf., 2002, 74, S1455-S1457.

43 V. Pipich, QtiKWS program: http://www.qtikws.de.

44 I. Grillo, in Soft Matter: Characterization, ed.R. Borsali and R. Pecora, Springer, Berlin-Heidelberg, 2008, vol. II, pp. 705-764. 45 P. Lindner, J. Appl. Crystallogr., 2000, 33, 807-811.

46 O. Glatter and O. Kratky, Small angle X-ray scattering, Academic Press, London, 1982.

47 A. Guinier and G. Fournet, Small Angle Scattering of X-rays, John Wiley \& Sons Ltd., New York, 1955.

48 F. Bonneté, S. Finet and A. Tardieu, J. Cryst. Growth, 1999, 196 403-414.

49 F. Bonneté and D. Vivarés, Acta Crystallogr., Sect. D: Biol. Crystallogr., 2002, 58, 1571-1575.

50 A. Tardieu, A. Le Verge, M. Malfois, F. Bonneté, S. Finet, M. Riès-Kautt and L. Belloni, J. Cryst. Growth, 1999, 196, 193-203.

51 S. Finet, F. Skouri-Panet, M. Casselyn, F. Bonneté and A. Tardieu, Curr. Opin. Colloid Interface Sci., 2004, 9, 112-116.

52 S. H. Chen and T. L. Lin, in Neutron Scattering, ed.D. L. Price and K. Sköld, Academic Press Inc. Ltd., London, 1987, vol. 23, part B, pp. 489-543.

53 J. S. Pedersen, Adv. Colloid Interface Sci., 1997, 70, 171-210.

54 J. B. Hayter and J. Penfold, Colloid Polym. Sci., 1983, 261, $1022-1030$.

55 S. H. Chen, Annu. Rev. Phys. Chem., 1986, 37, 351-399.

56 Neutrons, X-rays and Light: Scattering Methods Applied to Soft Condensed Matter, ed.P. Lindner and T. Zemb, Elsevier Science B. V., Amsterdam, 2002.

57 S. R. Kline, J. Appl. Crystallogr., 2006, 39, 895-900.

58 A. Isihara, J. Chem. Phys., 1950, 18, 1446-1449.

59 J. B. Hayter and J. Penfold, Mol. Phys., 1981, 42, 109.

60 J. P. Hansen and J. B. Hayter, Mol. Phys., 1982, 46, 651.

61 S. Doniach, Chem. Rev., 2001, 101, 1763-1778.

62 P. Baglioni, E. Fratini, B. Lonetti and S. Chen, J. Phys.: Condens. Matter, 2004, 16, S5003-S5022.

63 A. C. Dumetz, A. M. Snellinger-O'Brien, E. W. Kaler and A. M. Lenhoff, Protein Sci., 2008, 16, 1867-1877. 
64 D. I. Svergun, C. Barberato and M. H. J. Koch, J. Appl. Crystallogr., 1995, 28, 768-773.

65 E. Mylonas and D. I. Svergun, J. Appl. Crystallogr., 2007, 40, s245-s249.

66 A. K. Hunter and G. Carta, J. Chromatogr., A, 2001, 937, 13-19.

67 I. D. Kuntz Jr. and W. Kauzmann, Adv. Protein Chem., 1974, 28, 239-345.

68 M. Kozak, J. Appl. Crystallogr., 2005, 38, 555-558.

69 S. Finet and A. Tardieu, J. Cryst. Growth, 2001, 232, 40-49.

70 P. M. Tessier, S. D. Vandrey, B. W. Berger, R. Pazhianur, S. I. Sandler and A. M. Lenhoff, Acta Crystallogr., Sect. D: Biol. Crystallogr., 2002, 58, 1531-1535.

71 V. L. Vilker, C. K. Colton and K. A. Smith, J. Colloid Interface Sci., 1981, 79, 548-566.

72 A. George and W. W. Wilson, Acta Crystallogr., Sect. D: Biol. Crystallogr., 1994, 50, 361-365.

73 D. Asthagiri, A. Paliwal, D. Abras, A. M. Lenhoff and M. E. Paulaitis, Biophys. J., 2005, 88, 3300-3309.
74 H. Frauenfelder, G. Chen, J. Berendzen, P. W. Fenimore, H. Jansson, B. H. McMahon, I. R. Stroe, J. Swenson and R. D. Young, Proc. Natl. Acad. Sci. U. S. A., 2009, 106, 5129-5134.

75 V. Makarov, B. M. Pettitt and M. Feig, Acc. Chem. Res., 2002, 35, 376-384.

76 A. Paliwal, D. Asthagiri, D. Abras, A. M. Lenhoff and M. E. Paulaitis, Biophys. J., 2005, 89, 1564-1573.

77 B. L. Neal and A. M. Lenhoff, AIChE J., 1995, 41, 1010-1014.

78 M. G. Ortore, R. Sinibaldi, F. Spinozzi, F. Carsughi, D. Clemens, A. Bonincontro and P. Mariani, J. Phys. Chem. B, 2008, 112, 12881-12887.

79 J. R. Lu, Annu. Rep. Prog. Chem., Sect. C: Phys. Chem., 1999, 95, 3-46.

80 T. Arakawa and S. N. Timasheff, Biochemistry, 1982, 21, 6545-6552.

81 G. Scatchard, I. H. Scheinberg and S. H. Armstrong, J. Am. Chem. Soc., 1950, 72, 540-546. 